\title{
Study on the Strategy Model of Maintaining Temperature in Container
}

\author{
Ze Xi \\ School of North China Electric Power University, Baoding 071003, China \\ Caesarrayxz@gmail.com
}

Keywords: Genetic Algorithm, inverse proportional curves.

\begin{abstract}
Life and work often need to maintain the working fluid temperature constant within a container, such as bath in the bathtub. This paper develops a model of water temperature variation to determine the optimal strategy to achieve the goal about temperature maintaining. This paper devises three schemes for adding water. This article first sets a fixed value of injected water, then, study impacts of flow of water and time of adding water on water consumption. Next, changes the temperature of injected water to calculate the minimum water consumption of each scheme by utilizing Genetic Algorithm. Fit the numerical solutions into three inverse proportional curves. By comparison, obtain the optimal scheme as strategy for container.
\end{abstract}

\section{Introduction}

There are a lot of previous researches in the heat conduction and transfer, which can facilitate our comprehension of the problem.

For example, GunnebergF researched the heat transfer rate of water surface and impacts of air speed on dissipating heat that comes from the water surface [2]. Runbo Wei had great achievements in heat transfer between human body and the environment. ${ }^{[1]}$

This paper devises three schemes for bathing through both our own and others' researches.

Project One: Keep temperature stable near the optimum by adding water continuously, which is shown in figure $1(\mathrm{a})$.

Project Two: Make temperature fluctuate zigzag by adding interrupted water, which is shown in figure 1(b).

Project Three: Water temperature decreases smoothly down to $100^{\circ} \mathrm{F}$ at the end of bathing, which is shown in figure $1(\mathrm{c})$.

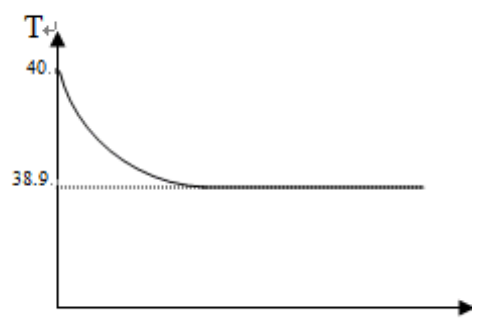

1(a)

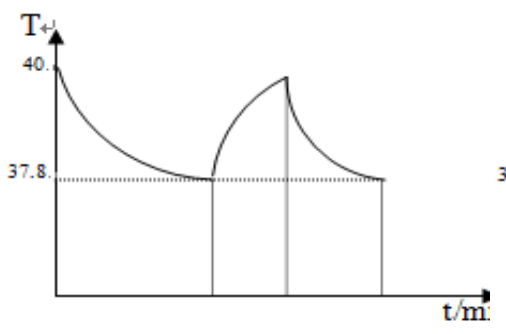

1(b)

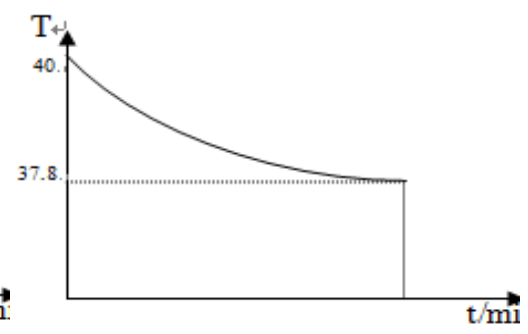

1(c)

Figure 1: schematic diagram for three projects

The following are two assumptions

$>$ Assume that the temperature of additional water is $120^{\circ} \mathrm{F}\left(\approx 49^{\circ} \mathrm{C}\right)$.

$>$ Assume that initial temperature of bath water is $104^{\circ} \mathrm{F}\left(\approx 40^{\circ} \mathrm{C}\right)$

\section{Model Building and Solving}

\subsection{Model One: stable temperature}

Initial temperature of bath water is $104^{\circ} \mathrm{F}$. We add water of $120^{\circ} \mathrm{F}$ into the bathtub continuously with a constant flow rate to maintain water temperature near the optimum until the finish of a hot bath. 
Duration of addition is 14.8 minutes. At last, we need to compute the total amount of additional water consumption. Schematic diagram is shown in figure 3(a).

Firstly, in order to cool the water to optimum temperature $38.9^{\circ} \mathrm{C}$, we let the sum of carried heat and dissipating heat of injected water and carried heat of escaped water is zero. The equation we obtained is as follow:

$$
\Psi d \tau+\Phi d \tau+(R+C) A_{p} d \tau+c \rho V_{w}\left(t_{1}-t_{0}\right) d \tau=0
$$

Where $\Psi$-- the heat dissipating capacity of water surface; $\Phi$--the heat dissipating capacity of the wall of bathtub; $R$-- quantity of radiant heat exchange between human body and environment; $C$-quantity of convective heat exchange between human body and environment; $A p$-- the surface area of human body; $V_{W}$-- the flow of additional water in unit time

At first, because the temperature of injected water is $120^{\circ} \mathrm{F}$, we calculate the minimum water consumption by utilizing Genetic Algorithm. Similarly, we change the temperature of injected water to obtain much more data. Fit the numerical solutions into inverse proportional curve in the least square method. The numerical solutions are shown below:

Table 1: numerical solutions

\begin{tabular}{ccccccccc}
\hline temperature $/{ }^{\circ} \mathrm{C}$ & 40 & 45 & 50 & 55 & 60 & 65 & 70 & 80 \\
\hline $\begin{array}{c}\text { minimum water consumption } \\
\text { correspondingly/L }\end{array}$ & 462 & 90 & 55.64 & 42.9 & 36.29 & 32.19 & 29.24 & 25.9 \\
\hline
\end{tabular}

\subsection{Model Two: fluctuating zigzag temperature}

Let the water temperature $\left(104^{\circ} \mathrm{F}\right)$ drops to $100^{\circ} \mathrm{F}$, which is the lowest temperature for bathing, Next, join a constant hot water flow of $120^{\circ} \mathrm{F}$, making the water temperature rise to a certain temperature value TP, as $\left(t_{1}-t_{2}\right)$ describes. At this point, assume the water temperature spontaneously drops to $100^{\circ} \mathrm{F}$ at the end of bathing shown in $\left(t_{2}-t_{3}\right)$ as described in model of temperature of bathtub water. We may figure out total amount of injected water consumption for this model. Schematic diagram is shown in figure 1(b).

We present the inequation at the "valley" between two curved faces, and we let the sum of carried heat and dissipating heat of injected water and carried heat of escaped water is over zero. The equation we obtained is as follow:

$\Psi d \tau+\Phi d \tau+(R+C) A_{p} d \tau+c \rho V_{w}\left(t_{1}-t_{0}\right) d \tau>0$

Ditto, we obtain the numerical solutions as shown below:

Table 2: numerical solutions

\begin{tabular}{ccccccccc}
\hline temperature $/{ }^{\circ} \mathrm{C}$ & 40 & 45 & 50 & 55 & 60 & 65 & 75 & 85 \\
\hline $\begin{array}{c}\text { minimum water consumption } \\
\text { correspondingly/L }\end{array}$ & 82.75 & 42.33 & 30.79 & 25 & 22.13 & 20.03 & 17.46 & 15.94 \\
\hline
\end{tabular}

\subsection{Model Three: decreasing smoothly temperature}

Add a constant flow of hot water at the beginning of bathing. Let the water temperature drops smoothly to $100^{\circ} \mathrm{F}$ which is the lowest temperature for bathing. At the moment, bathing is over. We may calculate total amount of injected water consumption for this model.

Schematic diagram is shown in figure 1(c).

According to what is described in Model Three, we obtain the formula:

$\Psi d \tau+\Phi d \tau+(R+C) A_{p} d \tau+c \rho V_{w}\left(t_{1}-t_{0}\right) d \tau<0$

Ditto, the solutions are shown below:

Table 3: numerical solutions

\begin{tabular}{ccccccccc}
\hline temperature $/{ }^{\circ} \mathrm{C}$ & 40 & 45 & 50 & 55 & 60 & 65 & 75 & 85 \\
\hline $\begin{array}{c}\text { minimum water consumption } \\
\text { correspondingly/L }\end{array}$ & 400 & 66.67 & 36.36 & 25 & 19.05 & 15.38 & 11.11 & 8.69 \\
\hline
\end{tabular}




\section{Model Results}

By calculating and comparing total amount of injected water consumption of the three schemes mentioned above, we can determine the optimal one. Noticeably, however, the temperature of injected water is changeable. The optimal scheme may change as temperature of injected water varies. Consequently, through analysis and calculation, we eventually come up with functions of total amount of injected water consumption with respect to water temperature, and draw function curves for simulation. Results are shown in Figure 2 as follow:

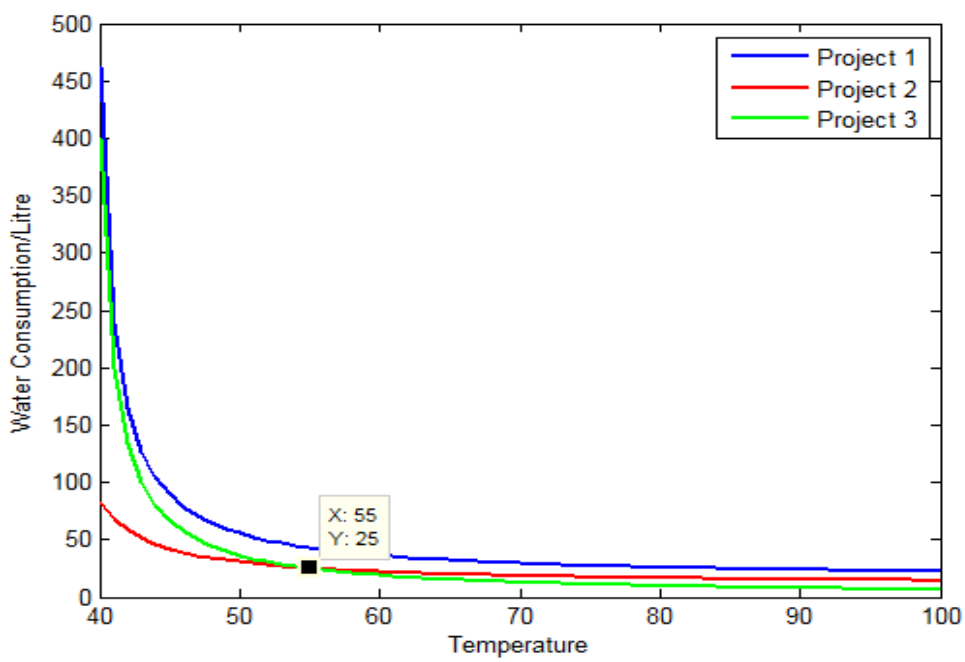

Figure 2: Function curves of three projects

From what displays in Figure 2 above, we can see that there exist different optimal solutions when the injected water temperature varies. Applicable conditions are shown as below:

Table 4: optimal solutions of various injected water temperature

\begin{tabular}{ccc}
\hline project & equation & applicable conditions \\
\hline project one & $y_{1}=447 /(t-39)+15$ & always maintaining the most consumption, no optimal \\
& solutions existing \\
project two & $y_{2}=291 /(t-36)+10$ & {$[40,54.61]$} \\
$\begin{array}{c}\text { project } \\
\text { three }\end{array}$ & $y_{3}=400 /(t-39)$ & {$[54.61,100]$} \\
\hline
\end{tabular}

Where: $y_{i}$-- total water consumption of project $\mathrm{i}$ in unit of $\mathrm{kg}, x$--temperature of injected water in unit of degree Celsius.

\section{Conclusion}

By calculating and comparing total amount of injected water consumption of the three schemes mentioned above, we can determine the optimal one.

This article gives the optimal strategy for saving water while bathing.

$>$ Users should adopt project two when injected water temperature varies between 40 and $54^{\circ} \mathrm{C}$.

$>$ Users should adopt project three when injected water temperature is over $54^{\circ} \mathrm{C}$.

\section{References}

[1] Wei Runbo, Human calculation method of heat exchange with the environment, Ergonomics 2 (1995): 39-42.

[2] Zhang Shunong, Tong Liang, Laboratory experimental study on heat transfer coefficient of the water, Water Protection 2 (1986).

[3] Li Jianpu, Fast computation of temperature field. Shanghai Normal University, 2010. 